\title{
Rapid Fabrication Techniques for Liquid Rocket Channel Wall Nozzles
}

\author{
Paul R. Gradl ${ }^{1}$ \\ NASA Marshall Space Flight Center, Huntsville, AL 35812
}

The functions of a regeneratively-cooled nozzle are to (1) expand combustion gases to increase exhaust gas velocity while, (2) maintaining adequate wall temperatures to prevent structural failure, and (3) transfer heat from the hot gases to the coolant fluid to promote injector performance and stability. Regeneratively-cooled nozzles are grouped into two categories: tube-wall nozzles and channel wall nozzles. A channel wall nozzle is designed with an internal liner containing a series of integral coolant channels that are closed out with an external jacket. Manifolds are attached at each end of the nozzle to distribute coolant to and away from the channels. A variety of manufacturing techniques have been explored for channel wall nozzles, including state of the art laser-welded closeouts and pressure-assisted braze closeouts. This paper discusses techniques that NASA MSFC is evaluating for rapid fabrication of channel wall nozzles that address liner fabrication, slotting techniques and liner closeout techniques. Techniques being evaluated for liner fabrication include large-scale additive manufacturing of freeform-deposition structures to create the liner blanks. Abrasive water jet milling is being evaluated for cutting the complex coolant channel geometries. Techniques being considered for rapid closeout of the slotted liners include freeform deposition, explosive bonding and Cold Spray. Each of these techniques, development work and results are discussed in further detail in this paper.

\section{Nomenclature}

$\begin{array}{ll}\text { AM } & =\text { Additive Manufacturing } \\ \text { CTE } & =\text { Coefficient Thermal Expansion } \\ \text { CWN } & =\text { Channel Wall Nozzle(s) } \\ \text { DED } & =\text { Directed Energy Deposition } \\ \text { DMLS } & =\text { Direct Metal Laser Sintering } \\ \text { EBF^3 }^{\prime} & =\text { Electron Beam Freeform Fabrication } \\ \text { EXW } & =\text { Explosive Welding } \\ \text { HIP } & =\text { Hot Isostatic Press } \\ \text { lbf } & =\text { Pounds of Force } \\ \text { LENS } & =\text { Laser Engineered Net Shape } \\ \text { LME } & =\text { Liquid Metal Embrittlement } \\ \text { LCUSP } & =\text { Low Cost Upper Stage Propulsion } \\ \text { MCC } & =\text { Main Combustion Chamber } \\ \text { MDDM } & =\text { Metal Direct Digital Manufacturing } \\ \text { MRL } & =\text { Manufacturing Readiness Level } \\ \text { MSFC } & =\text { Marshall Space Flight Center } \\ \text { SLM } & =\text { Selective Laser Melting } \\ \text { VPS } & =\text { Vacuum Plasma Spray } \\ \text { WJM } & =\text { Water Jet Milling or Water Jet Machining }\end{array}$

${ }^{1}$ Combustion Devices Design and Manufacturing Engineer, NASA Marshall Space Flight Center, Huntsville, AL 35812 


\section{Introduction}

Targe-scale booster and upper stage liquid rocket engines (>20,000 lbf thrust) are being considered and developed

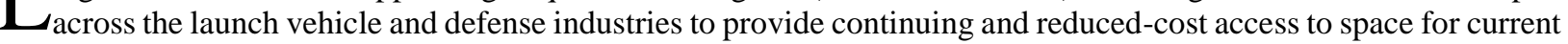
and future missions. These engines are derived from heritage designs that are being upgraded for payload capacity, heritage engines that are being evolved for affordability, and new blank-sheet engine designs. As engine manufacturers and government agencies are challenged to provide these engine solutions, the systems-level cost requirements are being flowed down to a component level to reduce associated design, manufacturing and tests costs while maintaining high performance. These costs can be reduced through elimination of processes, adopting and integrating new manufacturing techniques and design solutions, reducing inspections, or providing lower cost inspections.

NASA is researching methods and techniques of manufacturing for large-scale nozzles to reduce the overall lifecycle costs for liquid rocket engine component fabrication. Cost reduction is certainly a topic that has been addressed for many decades and several state of the art techniques have been considered to address this. In addition to cost, reduced production component build schedules is also being evaluated, which in most cases is synonymous with component cost. Although these cost reductions are being considered across all engine components, a fair amount of development and feasibility efforts for new manufacturing approaches are being investigated for regeneratively-cooled channel wall nozzles and combustion chambers. There are considerable differences between material considerations for high-heat-flux combustion chambers over materials used in regeneratively-cooled nozzles, but many of the manufacturing techniques for channel wall structures are similar, regardless of material combinations. The focus of these development efforts have been on nozzles, but are certainly applicable for combustion chambers with further development.

Modern manufacturing techniques are being advanced to address some of these cost reductions and increases in performance through design complexity. One example of this is the use of powder-bed additive manufacturing, often referred to as Selective Laser Melting (SLM) or Direct Metal Laser Sintering (DMLS), where design complexity adds no additional cost. This technology is being demonstrated and appears suitable for lower-thrust upper stage engine components. Subscale combustion chambers and nozzles have been hot-fire tested at NASA Marshall Space Flight Center (MSFC), where the fabrication of and hot-fire test planning for a 25,000-lbf thrust-class upper stage GRCop84 copper combustion chamber under the Low Cost Upper Stage Propulsion (LCUSP) program is pushing the limits of this technology ${ }^{1,2}$.

The LCUSP combustion chamber makes use of two additively-manufactured GRCop-84 axially-split halves, joined with a circumferential electron beam weld in the barrel section. This full copper chamber is then cladded with an Inconel 625 jacket and manifolds using Electron Beam Freeform Fabrication (EBF^3). The diameter of this chamber maximized the $250 \times 250 \mathrm{~mm}$ build area of the available powder bed machines. Larger-scale powder bed machines such as the EOS M400 3 and Concept Laser XLINE ${ }^{4}$ are increasing build capabilities (X,Y,Z) to 400x400x400mm and 800x400x500mm, respectively. This, however, still limits the size of components that can be manufactured in a single piece. Studies have been conducted to fabricate large-scale components using SLM pieces that integrate panels with axial and circumferential welds or brazes. While this design solution does have potential, it increases complexity of the hot-wall joints and must be traded against cost and fabrication schedules to build largediameter components. Another technology that has been reviewed for the complete (one-piece) fabrication of nozzles and other large-scale components is free-form blown-powder deposition. Although this technology has potential, the surface roughness, size limitations and fidelity of this process require further development at the time of this publication.

A regeneratively-cooled (regen) channel wall nozzle contains the coolant fluid within externally-machined coolant channels that must be closed out, as opposed to a tube-wall configuration that contains the fluid within the pre-formed tubes. Channel wall nozzles have been investigated for liquid engines due to the reduction in touch labor costs and more robust manufacturing processes relative to traditional tube wall nozzles 5 . The general configuration of a channel wall nozzle includes an inner liner that has a series of integral coolant passages on the backside of the hot wall and follow the internal contour of the nozzle. These passages are closed out using interface bonding (brazing, welding, non-metallic) or unbonded floating liner techniques, depending on the requirements. Once the liner is closed out, collection manifolds and flanges are added to complete the coolant circuit. This general configuration is shown in Figure 1. There are several techniques that have been used for formation of the liners (and closeout jackets/shells), creating the integral coolant channels and closeout of the coolant channels. 


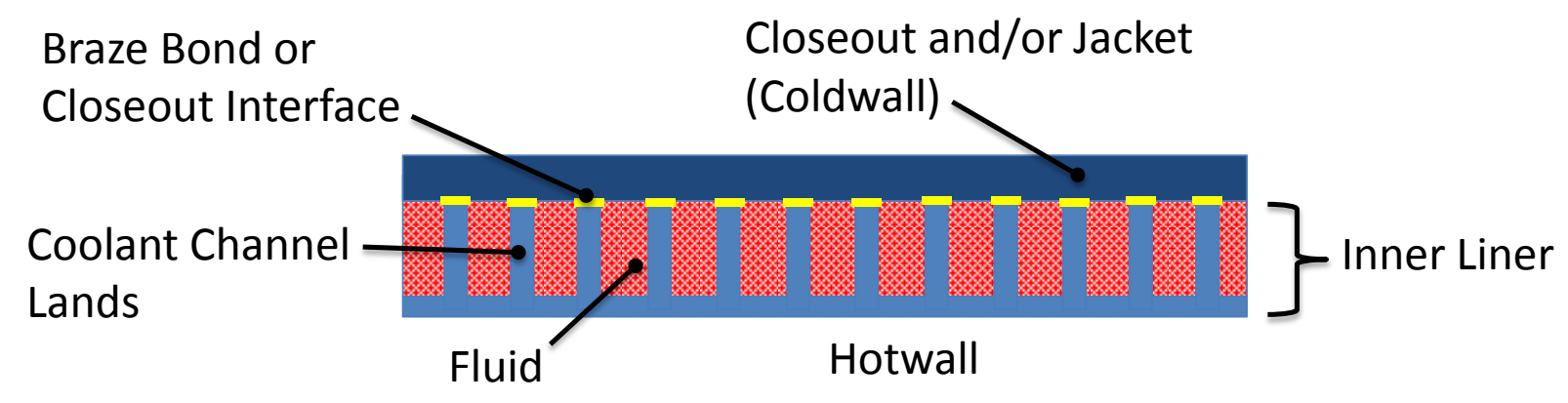

Figure 1. Configuration of channel wall nozzle liner and closeout.

The most challenging manufacturing operation within the channel wall nozzle is the closeout of the coolant channels. The closeouts require a high-integrity joint that meet several difficult requirements to contain the pressures of the coolant fluid, as well as withstand thermal shocks, static strains and dynamic loads within the material.

Electroplating is a heritage process extending back many decades for closeout of regen liners. Electroplating has primarily been used for the closeout of main combustion chambers (MCC), but regen nozzles have also been fabricated using this process. Nozzles are much more challenging due to the increased diameter and length. The coolant channels are filled with wax, then electrodeposited copper or nickel, depending on the liner material, is plated on the outer surface to closeout the coolant channels. The wax is later removed by melting and backpressure. A structural jacket can then be welded to the electrodeposited closeout and the distribution manifolds attached. Although several MCC configurations have been fabricated without the structural jacket, generally they are included to limit buckling at elevated temperatures. The electrodeposited technique limits the operating temperature and bond strength of the component at the plated interface. Additionally, the electrodeposition process can introduce impurities into the metal, causing issues in subsequent processing and often resulting in prolonged fabrication schedules.

Several state of the art techniques have been developed over the last couple of decades to address these channel closeout issues and are being used in development and flight production engines. These techniques include advanced brazing techniques (pressure and atmospheric), laser welding and deposition processes such as Vacuum Plasma Spray (VPS).

Brazing processes for nozzles have advanced to include pressure-assisted, often referred to as Hot Isostatic Pressure (HIP), brazing or vacuum compression brazing. These processes require an external jacket that is machined within tight tolerances to ensure that the inner mold line of the closeout shell is in close contact with the outer mold line of the slotted inner liner. The assembly process then requires the application of braze foil to select surfaces, assembly of the liner into the jacket, and sealing of the assembled parts ${ }^{6,7}$. The nozzle is then brazed using a pressureassisted braze furnace (elevated temperature, external pressure, and vacuum within the channels). The pressureassisted brazing technique for nozzles has been covered in several papers and patents ${ }^{8,9,10}$.

Various closeout techniques have been investigated to improve the traditional and pressure-assisted braze closeout processes. One of these techniques was a vacuum plasma spray (VPS) closeout demonstrated by NASA in the 1990 's ${ }^{11,12}$. This process used a plasma jet to deposit particles onto the external surface of a slotted liner to closeout the channels. These coolant channels were filled, or often electroplated, prior to plasma deposition, which added additional challenges, as previously described. The filler medium was then removed to expose the internal coolant channels. The VPS closeout process also exhibited several limitations. The material was deposited on a pre-heated liner at high temperatures, locally, in a vacuum chamber. The high base part temperature and plasma deposition required close matching of the material's coefficient of thermal expansion (CTE) to minimize the potential for cracking, although intermediate bond layer materials could be used to address some of this concern. The potential for cracking limited the size of components that could be built using this technique, since larger scale parts would exacerbate the CTE effects. Additionally, the process required a controlled vacuum chamber and environment, which could also limit the size of components fabricated using this technique.

A more recent closeout technique is the laser-welded sandwich-wall closeout technology developed by Volvo ${ }^{13,14}$. This fabrication technique laser welds a closeout metal sheet or shell over an inner liner that has been pre-machined with coolant channels. The lands for each of the coolant channels are dynamically tracked with an ultrasonic or X-ray device and welded on the top of the land rib, using the laser to penetrate through. This method produces a closeout of the channels, but requires significant offline inspections after the welding process due the blind welds. There is no 
direct means of inspecting these welds and the welds must be precisely tracked due the very thin ribs. This configuration also requires extensive tooling and specialized machinery to complete the tracking and welding, but has proven to be a reliable technique for large nozzles.

MSFC has been evaluating a series of techniques related to the fabrication of large-scale regen nozzles to reduce the fabrication cycle time and associated cost. The basic process for fabrication of channel wall nozzles includes:

1) Forming of the Liner

2) Channel Forming within the Liner

3) Closeout of the Coolant Channels and Attachment of the Structural Jacket

4) Manifolds

Some of the modern manufacturing techniques, such as SLM additive manufacturing, fall into several categories and the terminology used is based upon the traditional channel wall processes. It was also assumed that structural stiffeners or hatbands, if required, would be integral to the closeout and jacket, or assembled similar to manifolds. A basic survey of both existing and potential process techniques was completed that merited further research. These are shown in Figure 2. Some of these techniques have already been proven, while others are at a low manufacturing readiness (MRL) level for nozzles.

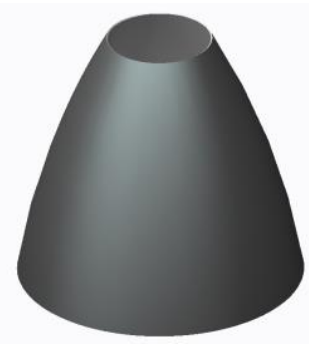

\section{Liner Forming}

- Forging

- Spin Forming

- Shear Forming

- Powder Metallurgy

- Freeform AM Deposition

- Powder-based Laser

- Wire-based Laser

- Arc-based Wire

- Multi-Piece SLM

- Platelets

- Explosive Forming

- Coldspray

- Casting

- Vacuum Plasma Spray
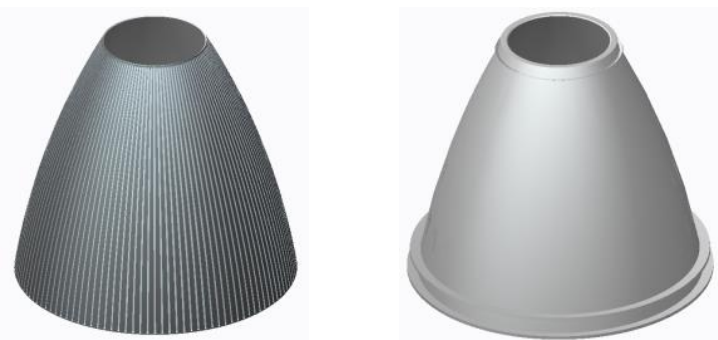

Closeout and Jackets

- Pressure Assisted Braze

- Standard Atmosphere Braze

- Multi-Piece SLM

- Vacuum Plasma Spray

- Electroplating

- Coldspray

- Freeform AM Deposition

- Wire-based Laser

- Powder-based Laser

- Arc-based Wire

- Explosive Bonding

- Ultrasonic

- Laser Welding

- Diffusion Bonding

- Platelets

- Casting

- Composite Overwrap

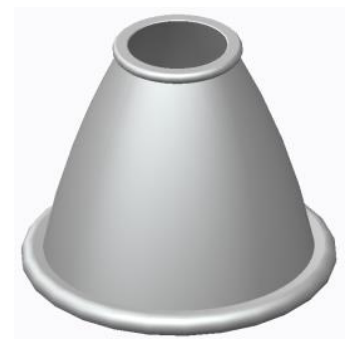

Manifolds

- Wrought and Machined

- Freeform AM Deposition

- Wire-based Laser

- Powder-based Laser

- Arc-based Wire

- Multi-Piece SLM

- Platelets

- Casting

- Molded Composites

Figure 2. Various fabrication processes for channel wall nozzle liners, slotting, closeout and manifolds.

This was not intended to be an exhaustive list of all available techniques, but provides several of the more mature industry technologies that have been or could be scaled for a large CWN. The channel closeouts and structural jacket could be fabricated from different materials, as well as separate manufacturing processes, but are combined for simplicity in the above figure. It is also known there are several complexities and variations within each of these fabrication techniques that are not covered in the graphic. Many of the techniques shown in the figure have been evaluated for use in chamber or nozzle technology, either at the specimen or full-scale level, although not all have been fully explored. There have also been new process developments for many of these techniques that merit further evaluation to build upon previous development work. 
There are three areas that will be discussed further in this paper: liner fabrication/forming, slotting, and closeout techniques. The primary manufacturing techniques discussed for liner forming include blown-powder laser deposition and arc-based metal deposition. Development data and examples using water jet milling will be detailed to address coolant channel slotting. Some of the development work being completed for channel closeouts will then be discusses, including freeform deposition additively-manufactured closeouts, explosively-welding closeouts and cold spray closeouts.

\section{Liner Fabrication}

The channel wall liner is the inboard-most subcomponent of the channel wall nozzle assembly and includes the hot-wall and subsequent back-side coolant channels. It is critical that the final liner configuration and material meet all the structural requirements, since this is often a thin-walled, high-strain component. The temperature delta across the hot wall is often several hundred degrees or more, so this component can fail in thermal, mechanical and combined loading strains. Typical liner fabrication involves the use of forgings or formed, welded, and spin-forged plate stock for the rough-shaped cones. These processes allow for an internal liner to be fabricated rough, then final machined prior to slotting of the liner. Large-scale liners often require welding of wrought plate stock, then bump forming into a cone shape. This cone is then spin formed to match the nozzle contour and recrystallize the axial (and circumferential) welds ${ }^{15}$.

A rapid-fabrication process for liners is being investigated and makes use of freeform additive manufacturing techniques for near net shape nozzles. These techniques are targeted for large-scale channel wall nozzles beyond the capabilities of powder bed fusion techniques. A variety of these fabrication techniques exist that use both powder and wire as feedstock, as well as various heating sources. The common sources for melting the powder or wire feedstock into freeform shapes include laser, electric-arc or plasma, and electron beam. The most common techniques are as follows:

- Blown Powder Deposition, also referred to as Laser Engineered Net Shape (LENS), Laser Freeform Manufacturing Technology (LFMT) or Direct Metal Deposition (DMD)

- Wire-based Laser Deposition, such as Laser Metal Deposition (LMD),Laser Deposition Technology (LDT), and Laser-Directed Energy Deposition (L-DED), among other names ${ }^{16}$

- Arc-based wire deposition such as Metal Direct Digital Manufacturing (MDDM) or Arc-Directed Energy Deposition (Arc-DED)

- Electron Beam Freeform Fabrication $\left(\mathrm{EBF}^{\wedge} 3\right)$

These techniques were down-selected to reduce raw material costs through near net shape fabrication of the liners, eliminate specialty tooling and welds, reduce complexity, and eliminate processes such as spinning and subsequent annealing cycles.

MSFC, along with industry partners, have created a series of freeform liners in subscale and large scale versions to evaluate and test the process. The focus of these liners has been blown powder deposition, although ongoing fabrication and evaluations are being completed using arc-based wire deposition. Trades have shown that these techniques could enable a significant reduction in wrought material to near net shape configurations and also eliminate several processing steps. Parts using the arc based deposition technique have shown an $85 \%$ reduction in material over traditional machining techniques ${ }^{17}$. Two 24 " diameter liners were fabricated using blown powder deposition, along with a series of vertical and angled panels used for mechanical testing and metallography. These nozzles and test specimens used Inconel 625 powder. The 24" diameter liners are shown in Figure 3. 

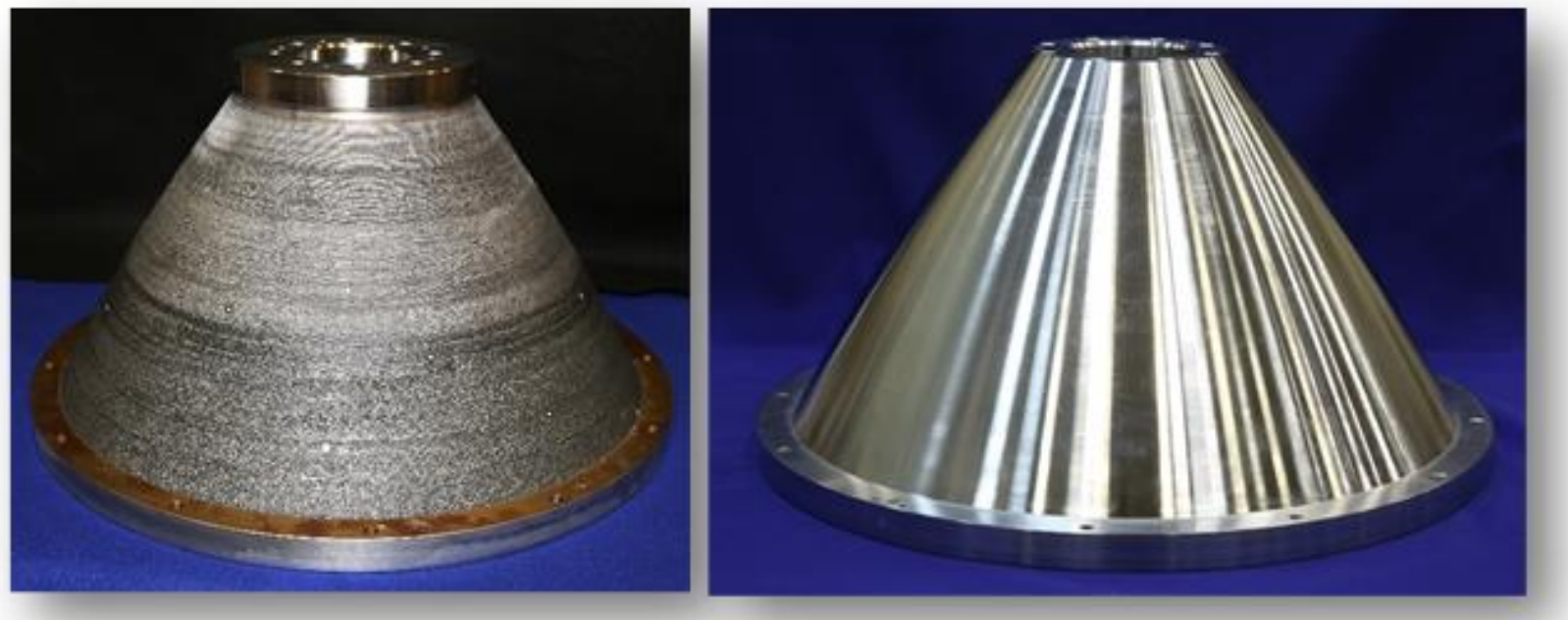

Figure 3. Blown powder deposition freeform liners fabricated, 24 inch diameter.

A cylindrical hoop 4140 steel plate was cut using water jet, final machined, and used as the build plate for the 24 " diameter (large) scale liners. The 4140 material was chosen to match the CTE of Inconel 625 and to reduce the cost of the large build plate. The liners were exposed to a localized purge during fabrication and were built in a canted position on a turntable with the objective of keeping the wall vertically oriented. A series of interim built-in cooling steps, generally 1" in height" were programmed to maintain adequate temperatures. The blown powder nozzle and laser were mounted to a robotic arm that would accommodate significantly larger nozzle liners. Following freeform deposition, the liners completed a stress relief at $1950^{\circ} \mathrm{F}$ for 1.5 hours in an inert environment, although they did not complete a HIP operation prior to machining. The liners were taken through several machining steps and water jet milling operations (described later). The rough freeform liner was machined at the MSFC Fabrication Shop. A 304 stainless tooling plate was fabricated at the piece part level and welded at the forward end stock of the liner to allow for fixturing. This allowed a method to rigidly install the liner onto the lathe for internal hot-wall machining.

Since minimal stock material was added to the freeform build, the liner was 3D scanned using structured light to meet required tolerances and to ensure full cleanup during each tooling pass. This adaptive machining process allowed for adjustments to be made quickly while hardware was still set up on the machine. A final scan was conducted, allowing a final, as-built contour to be developed and an internal mandrel to be match machined. This ensured a tight fit to the mandrel since the final wall thicknesses were less than 0.060 ". The liner was then bolted to the mandrel and the outer surface machined.

The blown powder deposition freeform process to build the 24" liners took less than 3 days, while the machining and tooling process took several weeks. This significantly reduced the fabrication cycle compared to a traditional spin forming or forging operation. The primary question was whether or not the liners met all mechanical properties using this process. MSFC has completed a series of tensile and LCF specimens that compliment these liners. There were minor debits to the mechanical properties, but they compared favorably to the solution wrought properties. These full properties are available, but not included in the extent of this paper. Additional liners have been built using this process, including the rough machined subscale liners shown in Figure 4. 


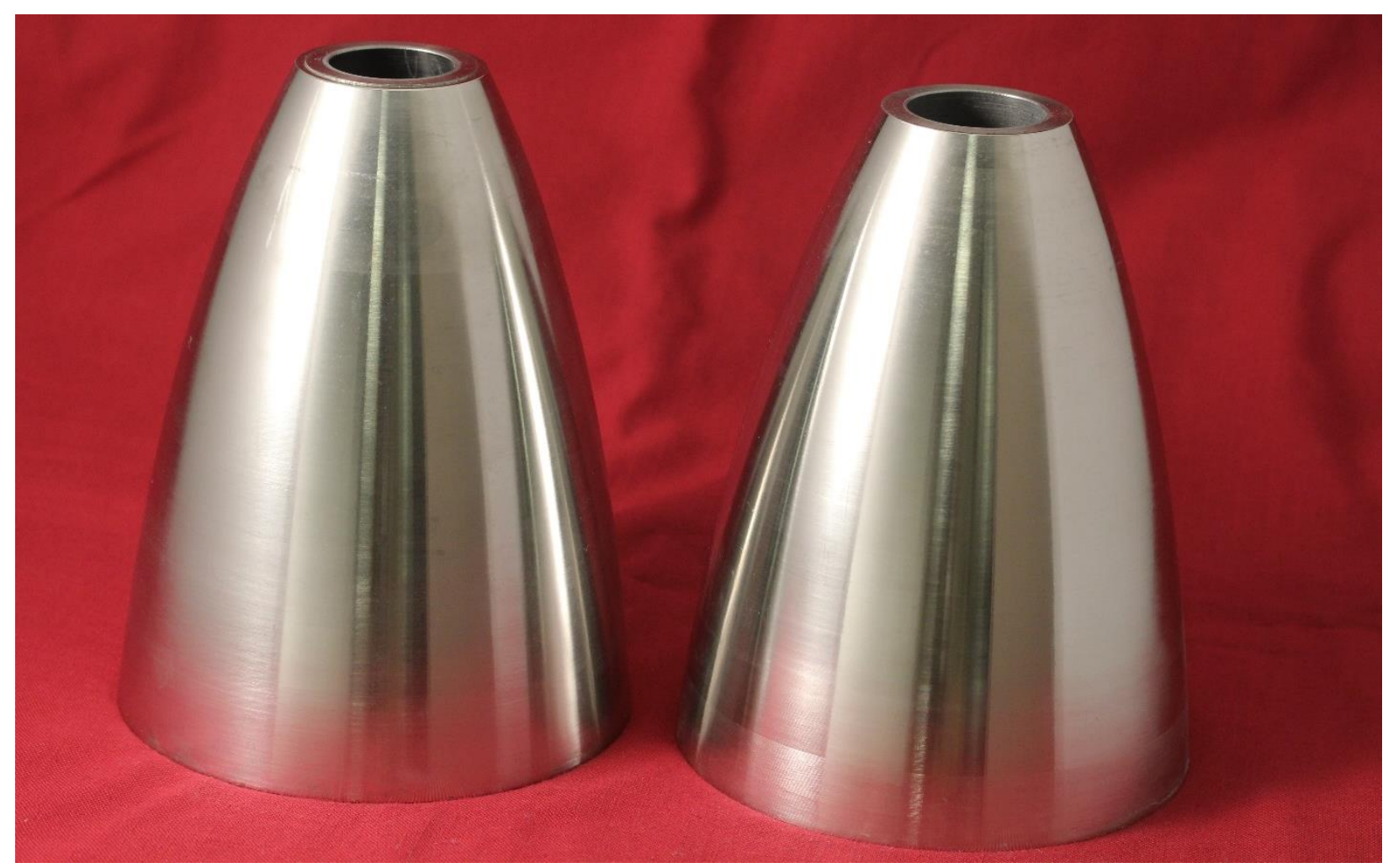

Figure 4. Subscale laser freeform powder deposition Inconel 625 liners.

Another process being evaluated for large scale liner fabrication is arc-based additive manufacturing, which has several variants. Cranfield University previously demonstrated a technique with various alloys called the Wire Arc and Additive Manufacturing (WAAM) technology for near net shape parts. MSFC has been working to advance a wire-based technique called Metal Direct Digital Manufacturing (MDDM) that uses integral sensors to continuously monitor the process. These sensors monitor the deposition process in real-time for bead geometry, temperature and part geometry to make corrections or identify anomalous build locations/features. The MDDM process has significant advantages, including high material deposition rates and the large wire $>0.060$ " diameter. Material property testing has also been conducted and shown the meet initial design requirements. Further evaluations of mechanical properties are an ongoing effort. The MDDM process is well developed for near net shape components with in-situ monitoring techniques. Pre-machined liners can be seen in Figure 5. 

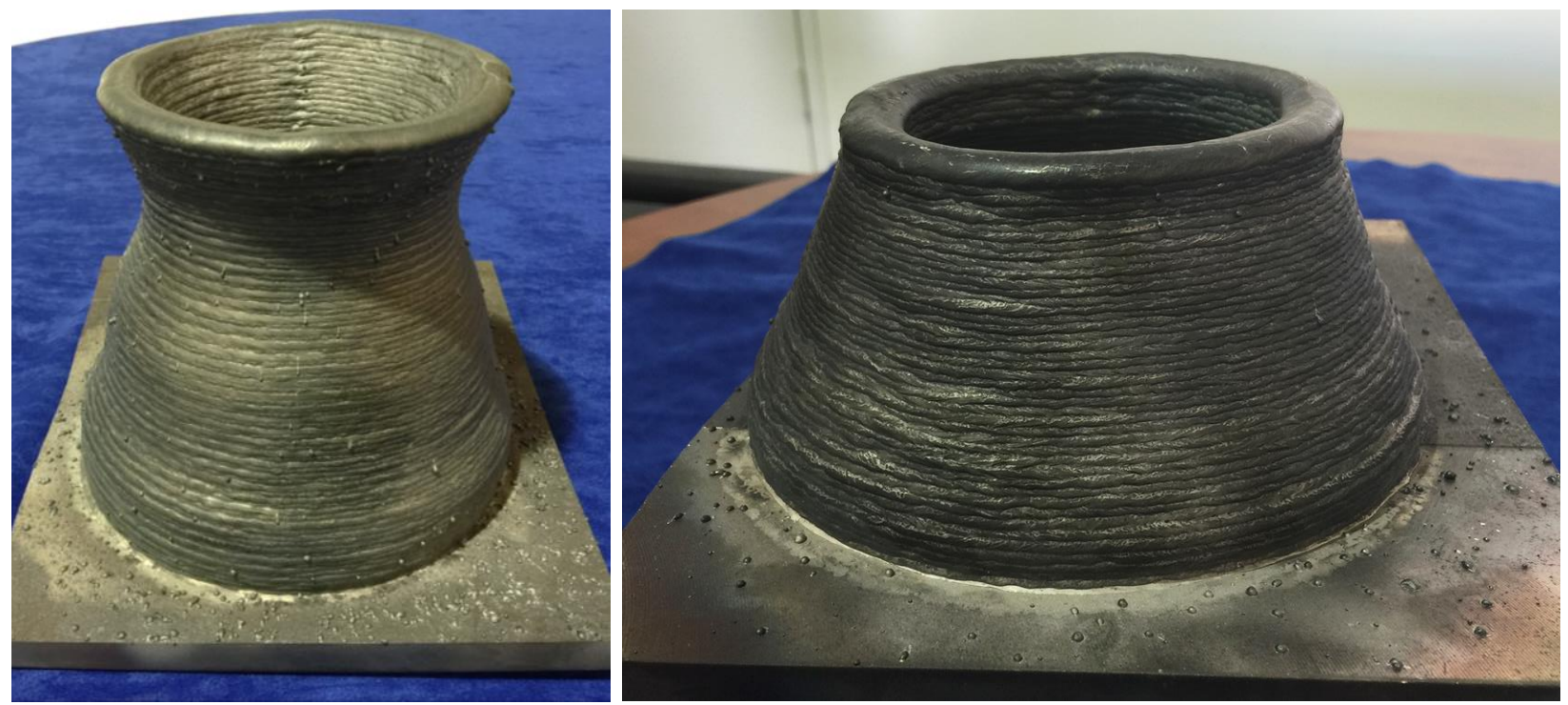

Figure 5. Example of Inconel 625 liners using arc-based freeform deposition, MDDM.

The blown powder deposition and arc-based wire deposition techniques have shown the potential to provide freeform fabrication of liquid rocket Channel wall nozzle liners. These freeform techniques are integrated with custom multi-axis machines, allowing for freeform builds inside purged chambers (or integral vacuum system), or can be adapted to multi-kinematic robot arms allowing for localized purges. This allows the techniques to be easily scaled to large nozzle structures and tooling fabrication. Hybrid techniques of this process are also being investigated, including freeform deposition of the liner to near-net shape and a subsequent cold spin forming operation to help with recrystallization of the material. Another Hybrid technique MSFC is evaluating is the combined additive manufacturing and subtractive techniques to minimize set up times for complete part processing.

\section{Water Jet Milling, Channel Slotting}

A variety of advanced techniques have been developed for forming coolant channels, which are typically milled into the liner using one or more slitting saws to achieve the desired channel widths. Slitting saws are advantageous since they offer fast material removal rates and milling is generally completed in a single pass ${ }^{18}$. This tool can be used on a variety of materials, but feed rates will be significantly reduced when milling in the stainless steel and Superalloy families. The channel geometry that can be milled is also limited to the cross-sectional profile of the slitting saw. While linear channels are the most typical, spiral channels have also be formed along the outer surface of the liner. Square end mills allow for nonlinear channels to be formed, but significantly reduced milling rates are required due to limited depth of pass and load on the end mill. An alternate technique being developed for forming coolant channels into the nozzle liner is abrasive jet milling, a specialized, blind, water jet milling process.

Water jet milling provides a 5-axis process for forming unique coolant channel geometries that were previously impossible to create or cost prohibitive to machine with typical slotting or end milling techniques. An example of these complex channels is shown in Figure 6. The process shows significant time savings for difficult to mill materials, such as Superalloys. Typical time savings are greater than $60 \%$ for the Superalloy family. Additional time savings can be achieved by employing more capable robotic manipulators than were used during these initial evaluations. This is based on flat panel and subscale contoured channel-milling nozzle data compared to traditional techniques. 

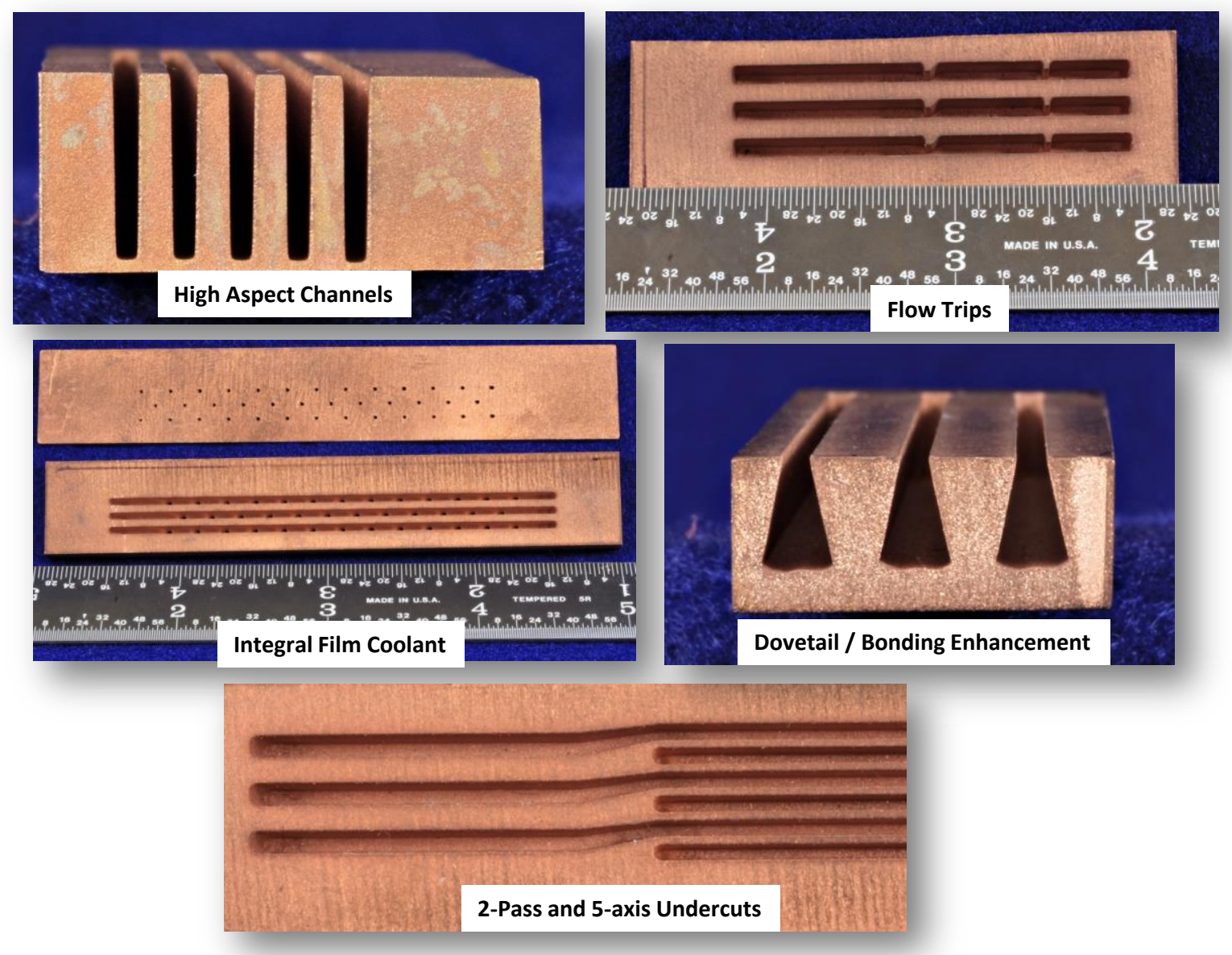

Figure 6. Examples of complex channel geometries created using advanced water jet milling techniques.

Abrasive water jet machining (WJM) is a method that is being evaluated to mill coolant channels in large-scale nozzle liners. There are several advantages to this process over traditional slotting or end milling. The water jet milling is a continuous 5-axis milling process, which allows for geometry not previously possible. The WJM process is adjusted based on the material being cut, similar to standard milling, and a variety of materials can be cut using the process, including the high-hardness materials such as Superalloys and soft materials such as copper.

The Superalloy family, such as Inconel, is the ideal candidate using this process since it mills in much the same way as a stainless steel would. This allows for significantly higher milling rates over a traditional slotting method. It is the softer materials that can be more difficult at the increased milling rates for water jet, and a time savings may not be realized if the design requires simplified axial channels. The WJM process does not impart high loads on the part being milled, so the hot walls can be thinned with minimal deformation of the bottom surface. This all but eliminates distortion from both the hot wall and channel lands. Subsequently, this allows thin hot walls of approximately 0.012 " to be used, which was previously very difficult to achieve with traditional methods.

A series of complex coolant channels have been demonstrated using WJM that were previously impossible or difficult to machine. These channels, previously shown, enable higher performance with increased surface area, reductions in wall thickness, integral film coolant and flow trips for 2-phase flow, high aspect channels and dovetailtype channels that offer increased backside (cold wall) surface area for bonding enhancements. Additional channel geometries have also been fabricated that integrate instrumentation ports with negligible disruption to channel flow, bifurcations, and varying channel depths, channel widths, and hot wall thicknesses. A series of large scale copper nozzles have been demonstrated in addition to an Inconel 625 nozzle liner. These can be seen in Figure 7. 

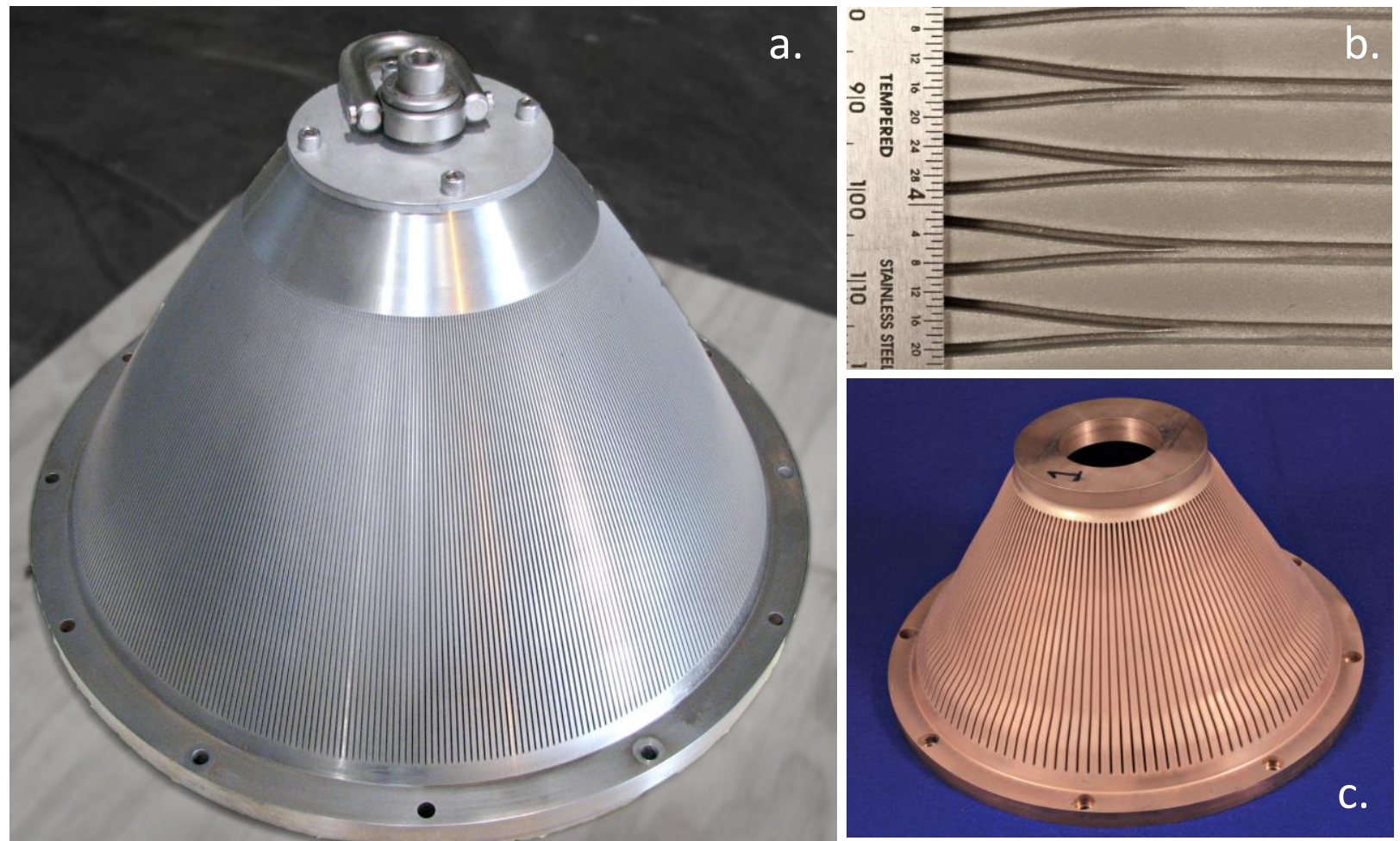

Figure 7. Subscale and full scale nozzle liners completed with water jet milling process: a. Inconel 625 24" diameter liner with varying depth channels; b. Bifurcated channels milled in Inconel 625; c. Axial channels in C-18150 Copper-alloy constant depth channels in mid-span and flared ends.

Throughout process development, a database of measurements was collected to understand process capability. A variety of complex axial channel geometries has been demonstrated on subscale and full scale liners. These channel geometries include constant depth, gradually-varying depth, and flared depth channels. The flared channels were particularly difficult for the water jet milling robot to traverse due to very high acceleration and deceleration rates in the rapid-depth changes. The process showed the ability to hold within $+/-0.006$ " in the flared regions, but had much tighter tolerances (within +/-0.002") within the constant depth and gently-sloping, continuously-variable sections. Standard slotting process development and production hardware has shown that $+/-0.004$ "is the typical tolerance for large scale liners ${ }^{6}$. Measurements taken from a flared liner is shown in Figure 8. The flared sections demonstrated some challenges due to the constantly changing accelerations of the water jet milling robot, while the constant hot wall thickness demonstrated extremely tight tolerance control. 
Depth Error Along Axial Stations of Liner 2D Cross Section

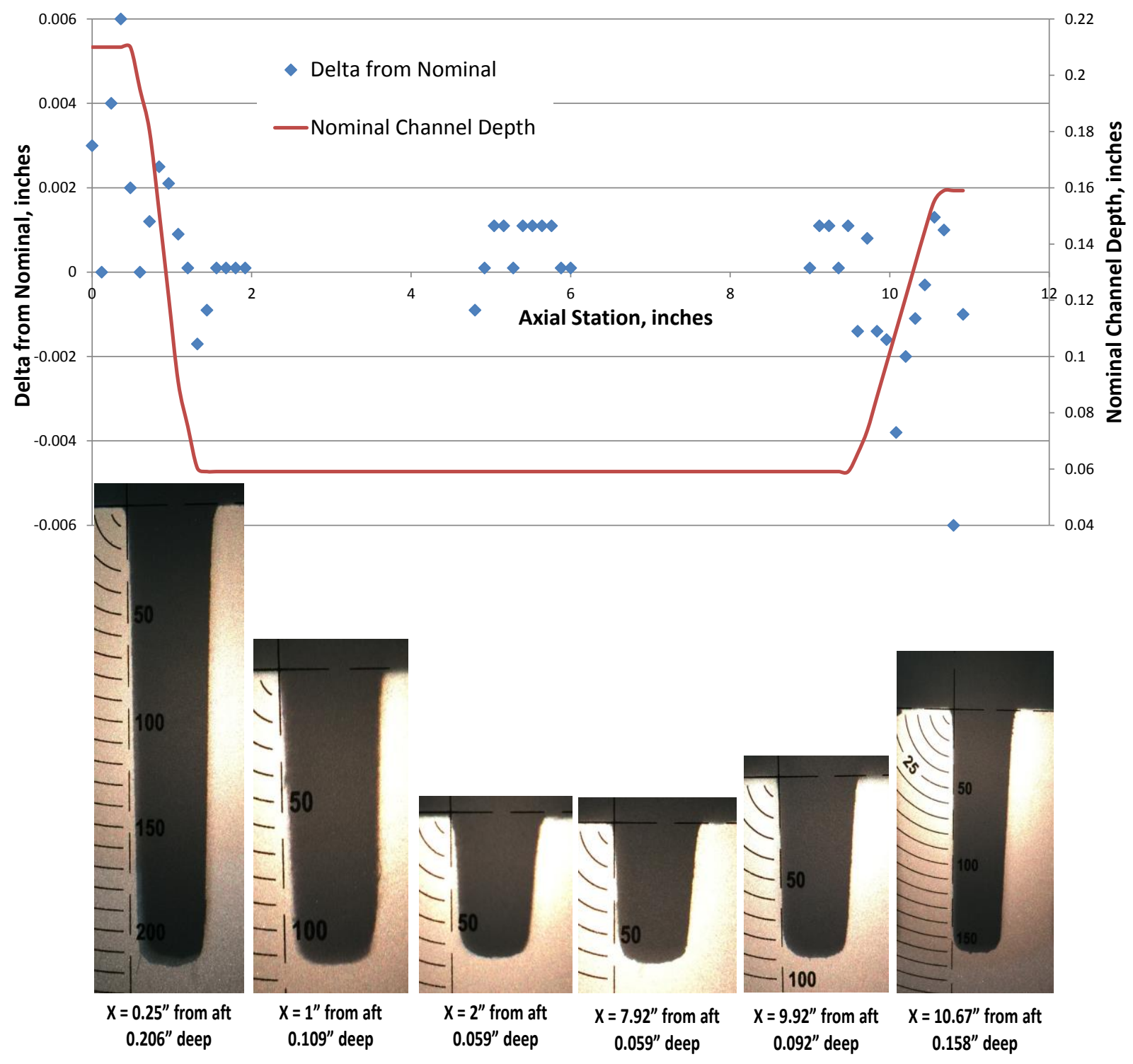

Figure 8. Water jet milling interim inspection data with varying depths and flared ends; nominal constant depth hot wall measurements were $+/-0.002 "$.

The water jet milling process continues to advance and is proving to be a very capable process for channel slotting. Process improvements continue to advance with closed-loop control to continuously monitor the process and the ability to shut down to avoid impacts to the liner hot wall. The low load of the milling head has shown no distortion or deformation to the hot wall. A variety of complex channel geometries have been demonstrated in various copper, stainless and Superalloys. The process is most capable for milling difficult alloys such as Inconel in the Superalloy family. This provides the most benefit for cost and schedule savings. The multi-axis water jet milling process has also shown the ability to create complex channels that were not previously possible with traditional techniques. Although the current state of the technology has shown increased milling rates over traditional slotting, it is expected that the WJM will also increase in speed for future applications if designed properly for the process and also if adapted to more rigid robots. MSFC is continuing to advance this process with industry partners as a viable technique in large scale complex milling operations.

American Institute of Aeronautics and Astronautics 


\section{Channel Closeout Techniques}

Several channel closeout techniques were evaluated for further development, including freeform laser deposition, explosive welding (EXW), and high velocity liquid cold spray. These techniques have been considered under previous industry and government feasibility studies, and the recent NASA research builds upon these and works to advance the technology readiness of these closeout techniques. The techniques vary widely and each have advantages and disadvantages. The freeform laser deposition allows for a visible bond that can be inspected as it is being deposited. However, the process is slower than the other processes mentioned and requires elevated heat input into the component. The explosive welding, or explosive bonding, for channel closeout creates a solid state joint that allows for multi-metallic materials, but uses high-energy explosives that add potential risk for component deformation. The liquid cold spray technique provides for a low heat input solution to minimize thermal effects on the parent material, but also limits filler material that can be used in the channels to bridge the channel width. Each of these techniques will be described in further detail.

\section{A. Freeform Deposition Closeout}

The freeform laser deposition is a large scale additive manufacturing process that creates a localized weld at each of the channel lands and bridges the channel width. This technique builds upon large scale cladding techniques that have been used for many years in the oil and gas industry, as well as techniques used in the repair industry for aerospace components ${ }^{19,20}$. The sandwich wall nozzle technology makes use of a similar laser deposition technique for manifold preparations (offsets) to weld on the closeout manifolds ${ }^{21}$. This cladding technique has generally been limited to a solid surface in previous applications.

The initial development of this technique used off-axis wire freeform laser deposition without filler material internal to the coolant channels. A variant using coaxial wire deposition is also being considered to provide more control for complex curvatures, such as combustion chambers. The wire and laser is traversed circumferentially around the nozzle with a majority of the laser focus being applied to the previous layer and partial focus on the channel lands. This prevents overheating and burn through of the channel lands. After the initial deposition layer, a traditional cladding process can be used to build up jacket support material or manifold welding offsets.

Experiments and feasibility of this technique have been recently demonstrated on Superalloys such as Inconel 625, 300 series stainless, aluminum alloys and also bimetallic bonding using copper (C-18150) to Inconel 625, as shown in Figure 9. The bimetallic bonding requires additional development work due to limited bond areas observed in initial development.

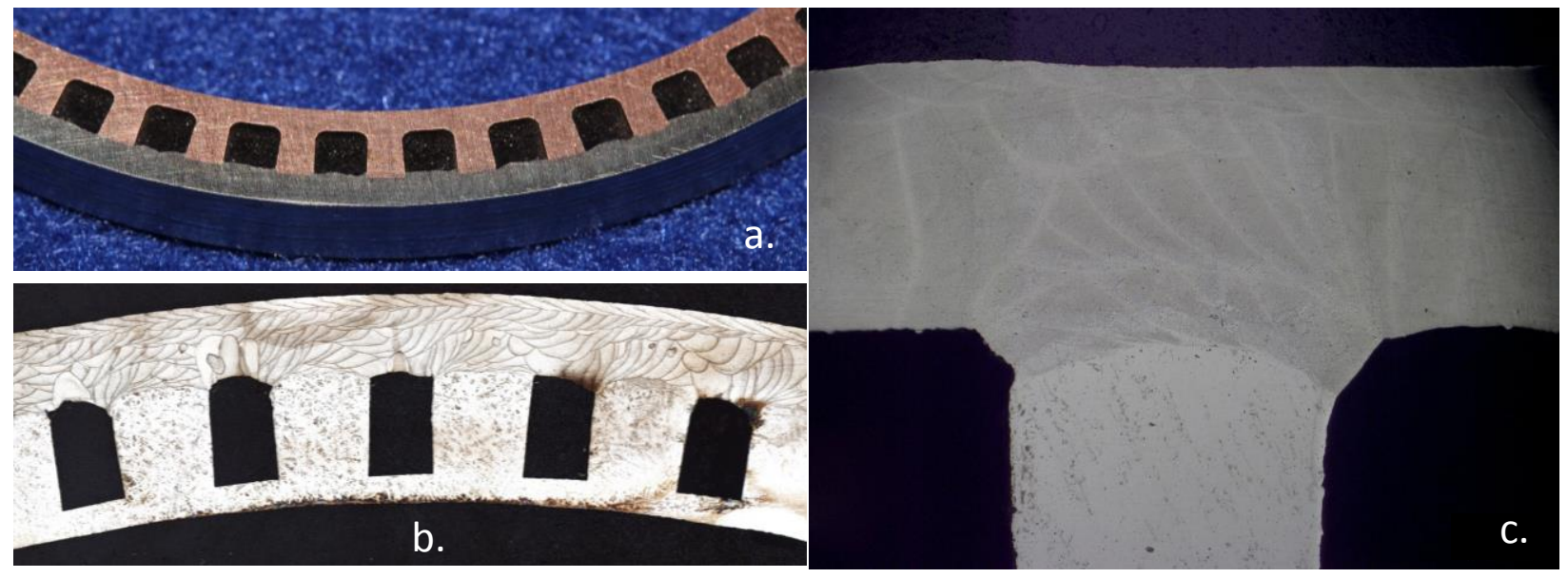

Figure 9. Examples of freeform deposition closeout technology for CWN liners. a. Early development work on bimetallic closeout (C-18150 to Monel and Inconel 625); b. 300 series Stainless closeout cross section; c. Cross Section of aluminum alloy closeout. 
A series of cylindrical hoop and subscale nozzle specimens have completed development using this process. Several samples were sectioned and metallography performed. Samples confirmed adequate bond lines at the channel land interfaces through metallographic and visual fillet inspections. The process has also been developed such that the closeout material does not deform or "slump" into the channel areas. There is some reduction in the flow areas, although generally less than 5\%, which can be accounted for in the design of the process. Additional samples are being completed to further optimize the process to minimize any channel to channel variations. A series of subscale liners have been completed using stainless and aluminum alloys. The laser processing and sensor packaging is mounted to a robotic arm with a localized purge, allowing this technique to be easily adapted to larger scale nozzles. Many of the sensors and system control developed under the freeform deposition liner fabrication can easily to be adapted to this technique for process monitoring and control. A partially-closed and fully-closed liner are shown in Figure 10. The process also allows for integral manifold preparations within the same setup.

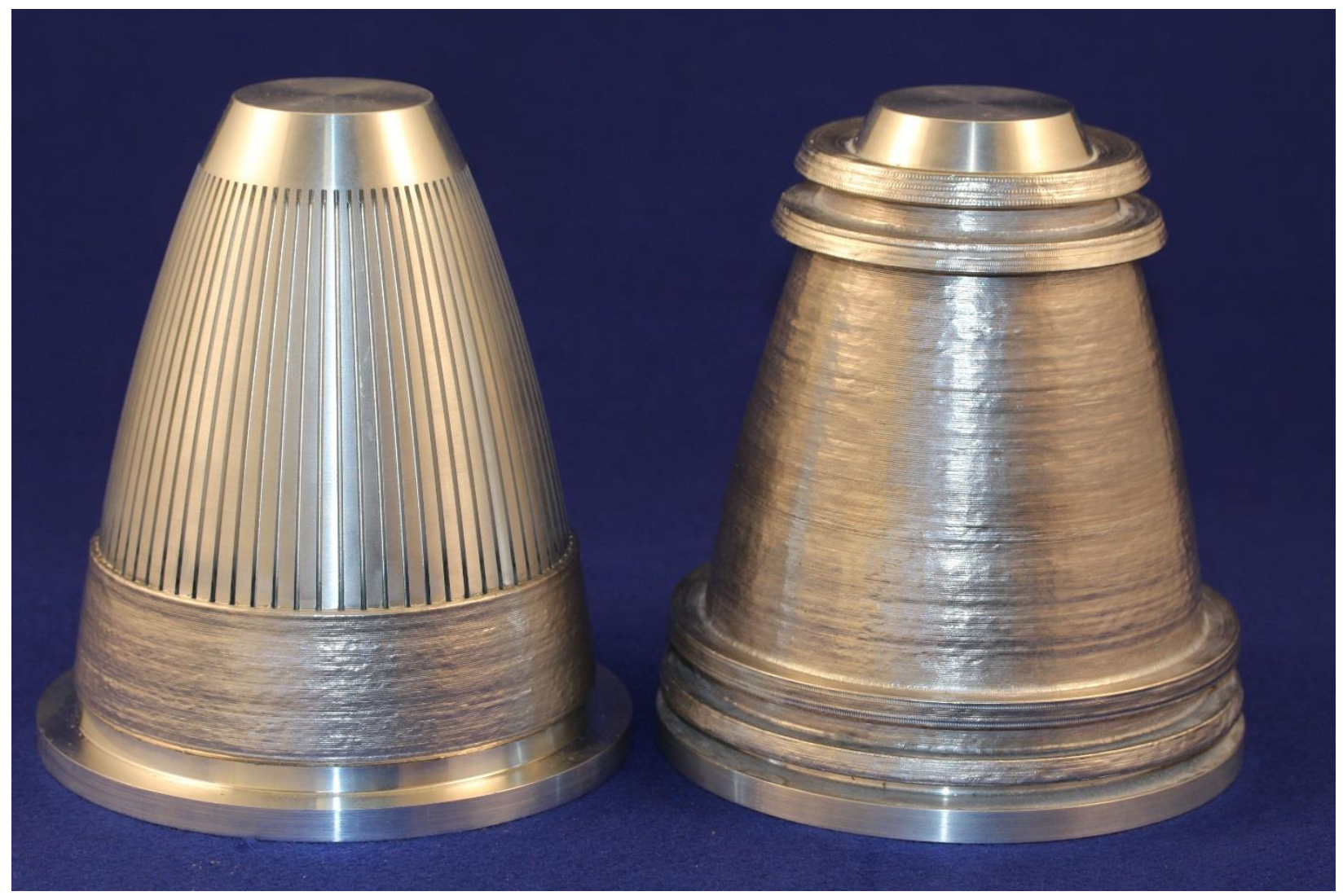

Figure 10. Freeform deposition closeout of nozzle liners, without filler materials.

NASA is continuing to develop the freeform deposition closeout for subscale and large scale nozzle applications. This process has shown potential for closeouts in a variety of alloys and the opportunity for bimetallic and multimetallic applications. The bond line is monitored during the process, which allows issues to be caught mid-process and potentially repaired. Optimization of the process is also being completed to enable uniform channel geometries and also increases in deposition speeds.

\section{B. Explosive Bonding}

Explosive welding was previously demonstrated by Battelle Labs under a NASA contract as a method for solid state closeout of combustion chambers, turbine components and channel walled, cooled wind tunnel components. This program resolved several technical issues with explosive welding during the early and mid-1970's at end of the Apollo program and helped advance the technology beyond a lab environment. The EXW technology development focused on forming of the channels, followed by their closeout. A series of experiments were conducted on flat plates, complex 
curvatures and wedges for a combustion chamber and wind tunnel nozzle wall structure. Although the study resulted in high-strength, robust bonds, several gaps existed in this research, including filler materials, tooling and configuration, and post-processing.

Starting in 2013, NASA and industry partners started a project to continue development work, building upon and advancing the previous work from Battelle. EXW technology offers several advantages for use in regen nozzles. The process is scalable to large components and has been used for explosive forming operations up to 8 feet in diameter and 10 feet in length for nozzles. The process is solid state, where the heating is extremely localized on the surface of the cladded and flyer material and generally inconsequential ${ }^{22}$. This provides advantages for similar and dissimilar metals, often providing a bond that has higher strength than the parent materials.

There were several motivations to explore the explosive bonding process further for nozzle applications. The first motivation was the reduced cost compared to traditional processes. The tooling and facilities for the process are greatly simplified where the primary tooling is the backing mandrel. The tolerances required for the liner and closeout shell and slotted liner are also significantly reduced, providing additional cost savings in the process. The second advantage is the strength of the bond joint, which has been demonstrated for channel walled structures to be equivalent to or higher than the base metals being explosively welded.

The EXW joint offers the potential to conduct post-bonding operations such as manifold welding without compromising the integrity of the channel closeout. With a brazing operation, the downstream process must limit the use of secondary heating operations to avoid remelt of the braze alloy. The third motivation of the EXW process is the use of dissimilar metals, offering the potential to further optimize design requirements such as decreased weight and increased heat transfer. This technique allows for design opportunities not previously possible with traditional joining techniques.

Early development work during the recent EXW channel wall nozzle task explored bonding without the use of any filler materials within the channel structures. It was discovered that, in order to maintain geometry of the channels, a channel filler material or channel support tooling would be required. The previous research for EXW made use of low melt alloys and carbon steel for the channel filler support material. These support materials were removed by heating to flow material from the channels or acid leaching to etch the filler ${ }^{23}$. There were significant challenges with each of these removal methods and each presented risks to the bond line.

The low melt alloys that were previously used in the Battelle process development included Zinc and Bismuthbased alloys (Bi-26.7Pb-13.3Sn-10Cd and Bi-42Sn) ${ }^{24}$. These Zinc and Bismuth alloys were melted into the channels and later heated to remove. Depending on the alloys being explosively bonded, these low-melt alloys present a concern with liquid metal embrittlement (LME) and early failure of the joint if the proper conditions exist ${ }^{25}$. Electroplating of nickel was also applied over the surface of the Zinc and Bismuth fillers and later ground from the surface of the channel lands or ribs. Beyond the LME concerns, the melting of the alloys from the channels could also prove to be a difficult process. Surface tension of the alloys resulted in trapped material, which had to be forced from the channels by mechanical methods. These concerns with the low-melt alloys prompted additional research in the channel filler materials for the recent development testing.

The carbon steel filler alloys also presented issues during the removal process. These fillers were removed with a $50-50$ nitric acid-water solution at $180-190^{\circ} \mathrm{F}$. The etching process required considerable time and the solution had to be continuously refreshed to be effective. This presents some challenges for the nozzle configuration due to the small cross-sectional area and limited surface area on each end. Mechanical means were also used during the previous development program. The carbon steel provided a rigid support structure to maintain the geometry of the ribs, but also provided some opportunities to improve upon for the removal process.

A series of fillers were explored in the recent Marshall development effort. These included both metallic and nonmetallic channel fillers. The requirements for the channel fillers included:

1) Maintaining channel land and hot wall geometry during bonding,

2) Simplifying the removal process,

3) Material compatibility with most liner and cladding materials.

The materials explored in the development included Inconel 625 to Copper Alloys and Inconel 625 to Inconel 625. Additional materials are being explored in continued development of this process in both the stainless, aluminum and Superalloy families. The explosive bonding process allows for bonding of dissimilar metals that were previously either not possible or very difficult to bond reliably with high integrity. This process enables further optimization of nozzle structures using materials for increased heat transfer properties and weight. 
The initial EXW 2D and 3D experiments included flat plate and cylindrical bonding demonstrations. These were primarily used to determine the appropriate fillers to maintain current channel designs and demonstrate removal. The fillers initially investigated were:

- $\quad$ Eutectic Salts

- Dissolvable Ceramic

- 1000 series aluminum

- Lead

- $\quad$ Mild Steel

- Lead-Tin

The filler materials were evaluated for rigidity during the bonding process and their ability to hold channel geometry, in addition to ease of removal. Examples of the filler alloys, removal pictures, and basic testing is shown in Figure 11.
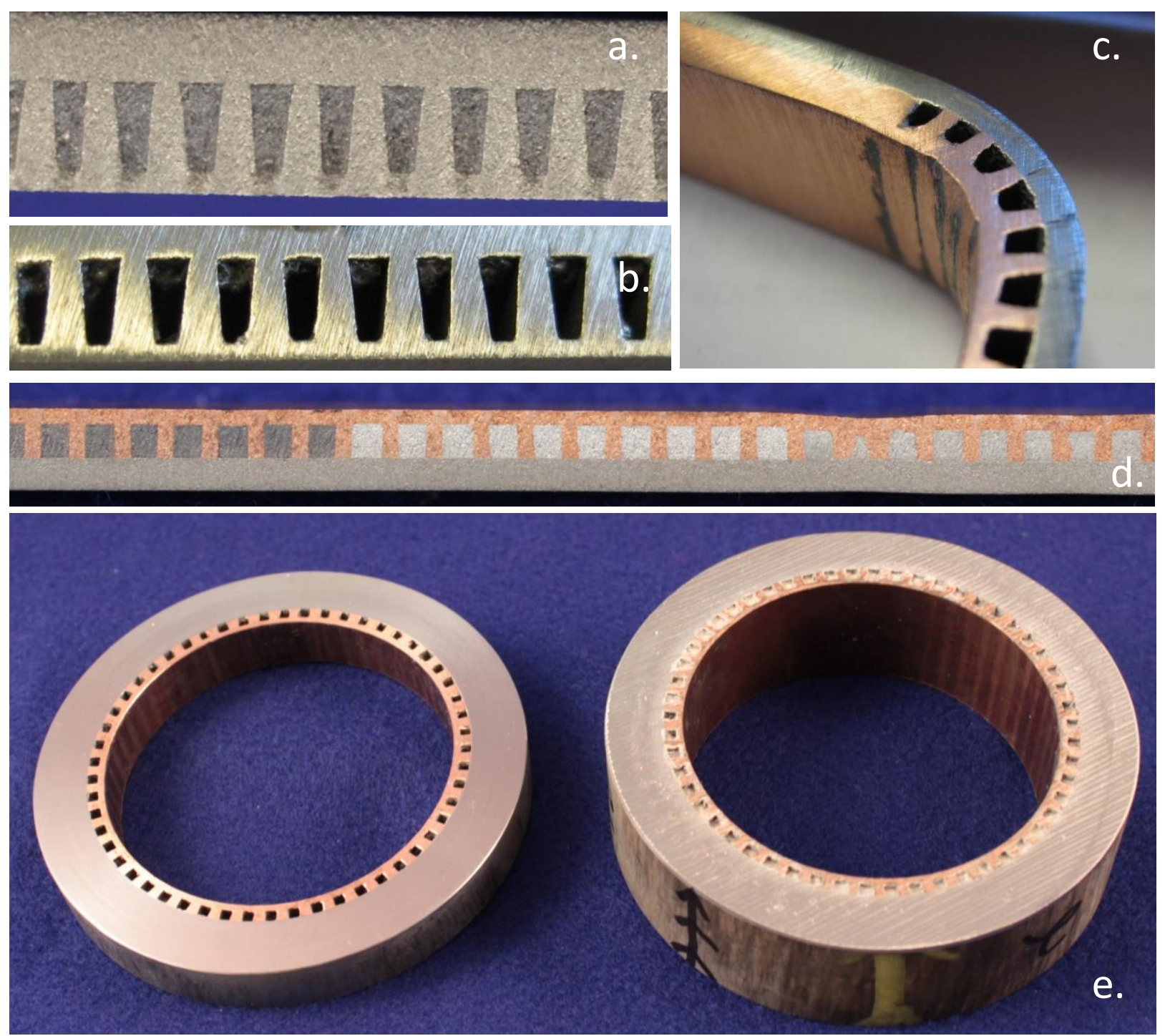

Figure 11. Fillers within channels for Explosive Bonding Operations: a. Aluminum Filler in Inconel 625 after bonding pre-removal; b. Initial removal of filler from Inconel 625; c. Bend test of Cu-alloy to Inconel 625; d. Various metallic fillers in Cu-alloy to Inconel 625; e. Eutectic salts shown after removal on the left and preremoval on the right. 
The eutectic salts demonstrated the ability to maintain channel geometries during bonding and were removed with warm water or steam. They were melted into the channels at $475^{\circ} \mathrm{F}$ and soften at about $415^{\circ} \mathrm{F}$. Agitation or direct spray impingement into the channels allowed for accelerated removal rates. There were a few issues noted, though, with the eutectic salts, including material compatibility with select materials. The hygroscopic nature of the salts also caused some debonds in trailing edges and some migration into the bond lands. Future EXW with the eutectic salts would require a process to remove additional moisture from the filler to prevent these issues. The dissolvable ceramic was evaluated, but bonding experiments revealed that it was too porous to maintain adequate channel geometry.

The metallic fillers all worked well to maintain channel geometry. The best metallic fillers were the mild steel and aluminum, since the lead could not be removed with etchants. Removal of the mild steel was an extremely slow process, while removal of the aluminum was much faster. Aluminum would be the preferred metallic filler due to its ability to form into the channels and its simplified removal process. The 1000 series aluminum was removed using 2.5M Sodium Hydroxide $(\mathrm{NaOH})$ at $90^{\circ} \mathrm{F}$.

Following initial flat plate and subscale contoured surface development hardware, a large-scale CWN was attempted to further evaluate the process. The nozzle liner was the previously-machined, water jet milled, blown powder freeform deposition hardware. The same tooling that was used for machining was also designed for commonality as the backup mandrel for the EXW process. The mandrel was fabricated such that it was matchmachined to fit the hot wall with minimal gap using a structured light scanning technique. A 0.080 " thick Inconel 625 closeout shell was fabricated using spin forming to allow an adequate stand-off gap for acceleration during the EXW event. The build plate was maintained on the liner as tooling through all operations, but was removed during the explosive bonding operation due to the plasma jet. The build-up of the liner assembly is shown in Figure 12, in addition to the final bonded liner.

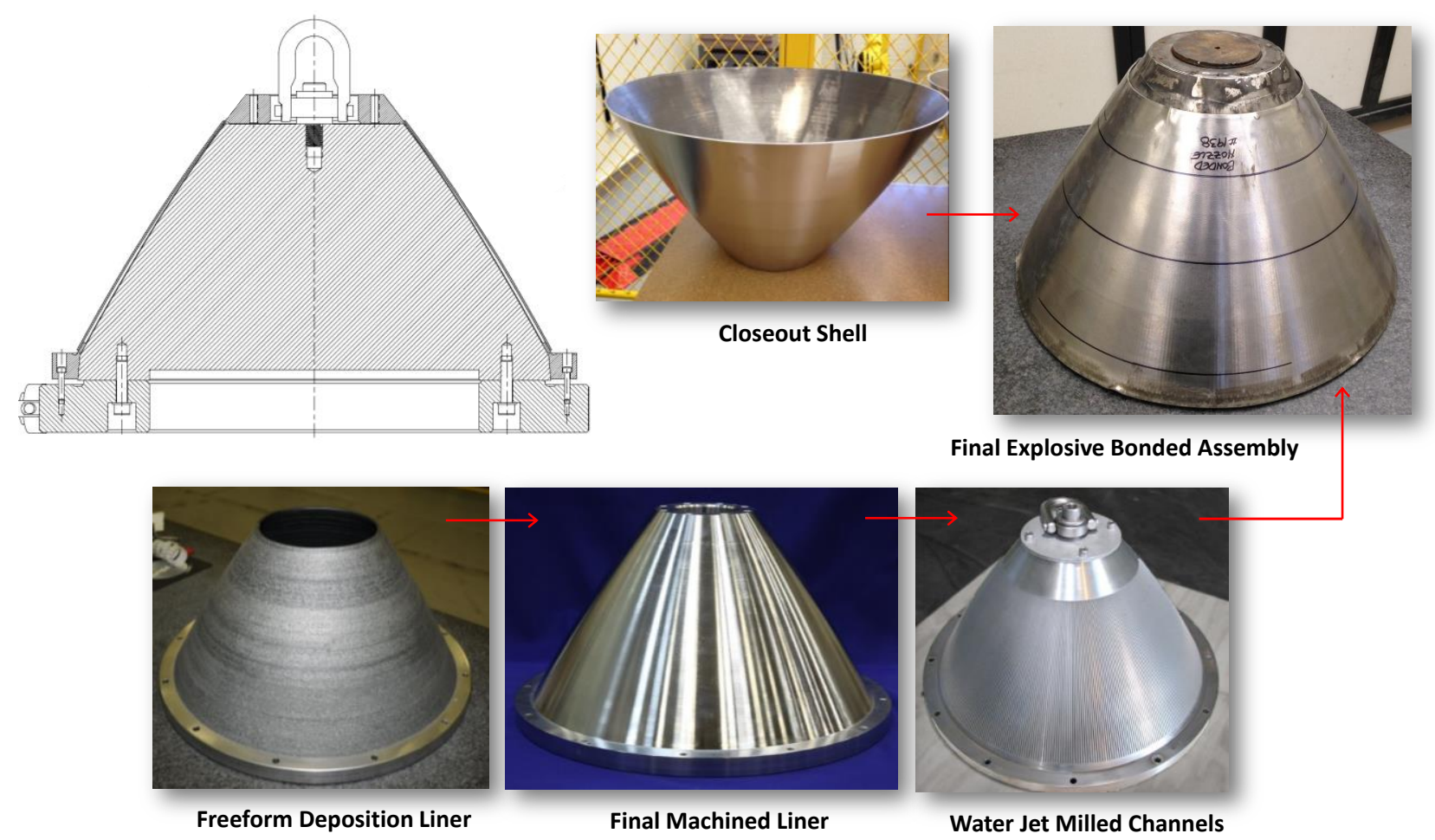

Figure 12. Assembly of explosively-bonded Inconel 625 liner with Inconel 625 closeout shell.

The liner maintained the basic shape with some slight deformation within acceptable tolerances. The channels did see some deformation, but it was known that additional optimization was necessary. The channels were filled with the 1100 series aluminum for this demonstration. This liner provided a demonstration that the process could be easily scaled up and maintain tolerances without significant deformation along the contoured wall. 
The explosive bonding process has demonstrated potential for a variety of Copper, Stainless and Superalloys to maintain adequate bond strength and axi-symmetric contour geometry using the EXW process. Additional bonding demonstrations and optimizations are being conducted on channel fillers, tooling and processes. Metallography and mechanical test specimens were also completed and are continuing to be reviewed.

\section{Liquid Cold Spray}

Cold Spray is a technology that has been previously evaluated for rocket component fabrication, primarily for coatings ${ }^{26}$. The cold spray technology accelerates particles in a high velocity gaseous jet stream, using kinetic energy to bond to a substrate or previously sprayed layers. The accelerated powder is the alloy that is of interest for bonding or coating of the substrate. This technology has advantages since it is a solid state bonding process, allowing lower temperatures to be maintained ${ }^{27}$. Maintaining these lower temperatures during bonding operations in cold spray, and similar in the EXW process, is critical for many alloys to maintain adequate properties. A recent development of the cold spray technology takes advantage of extremely high pressure pumps, typically 90,000 psi or less, accelerating the powder using a liquid to significantly increase the velocity and subsequent kinetic energy of the bonding operation $^{28}$. The liquid flashes to avoid any wetting of the metallic particles. This has advantages over gaseous cold spray due to the increased velocity and aids with cleaning of any surface oxides as the powder is being bonded. The cold spray equipment and ejection nozzle is mounted to a large-scale robot, which also allows for large-scale components to be fabricated.

A feasibility study was completed using the high-velocity, liquid-accelerated cold spray technology to build up and closeout channels with C-18150 powder. The liquid cold spray process allowed for a larger distribution of the powder size while maintaining identical chemistry. The C-18150 was of particular interest for this technology due to decreased properties as it is exposed to elevated temperatures, such as brazing. The basic process for the liquid cold spray is shown in Figure 13.

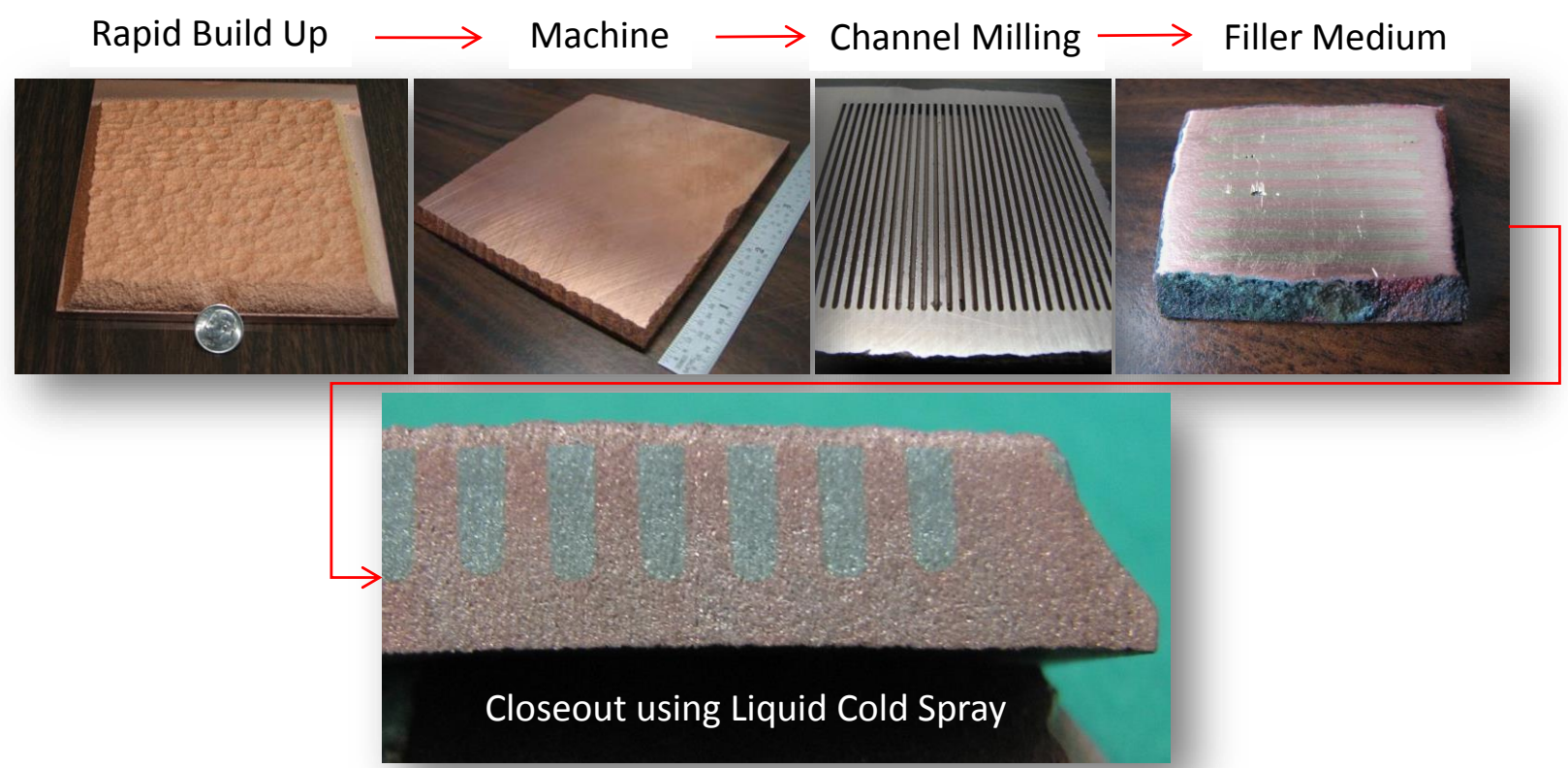

Figure 13. Flat plate samples using Liquid Cold Spray for rapid material deposition and closeout.

The initial experiments demonstrated build-up of flat plate specimens. A backer plate was used to aid with the initial bond layer of copper powder, but generally not maintain good adherence. However, the powder did bond to itself, allowing for build-up of material. A series of flat plates were completed using the liquid cold spray and later milled with channels. A similar development effort evaluating channel filler materials was completed. A series of nonmetallic fillers, such as the eutectic salts, high compressive strength epoxy and adhesives, were evaluated for the liquid cold spray based on similar requirements as the EXW process channel fillers. It was discovered that the liquid cold spray process quickly eroded the non-metallic fillers, making a metallic filler necessary. For initial feasibility, and 
based on limited budget, a brass brazing material and silver solder were used in the channels as fillers. It was known by the end of the project that the channel fillers would require significant development for this process due to erosion characteristics of the high-velocity powder.

Further experiments were completed that demonstrated basic build-up of cylindrical shapes to a backer mandrel. The flat plates and simulated parts later completed HIP, followed by solution treat and age ${ }^{29}$. Mechanical and metallographic inspection were also completed. This project showed the potential to fabricate near net shape components using the liquid cold spray technology. The MRL of this technique is low and would require optimization of traversing patterns for larger scale parts, in addition to development of the channel fillers, to provide a more robust removal process.

\section{Interim Inspection of Nozzles}

An integral part of the nozzle manufacturing process is inspection to aid with machining, slotting, heat treatment, welding and brazing, component assembly and final integration. Many of these processes are often controlled with complex tooling. Although several inspections are used during hardware fabrication, they have traditionally been thought of as "expensive," only used if absolutely necessary, and as a final quality buy-off of hardware at the end of processing. Modern inspection techniques have advanced, allowing for rapid data collection with the interest in reducing costs associated with interim engineering process inspections, as well as final quality control inspections. A technique that is being explored across the aerospace industry for small and large component fabrication is optical measurement techniques such structured light scanning, photogrammetry and laser scanning ${ }^{30}$.

Although this structured light, or full-surface optical scanning, technique was briefly described in other sections of this paper, it is worth noting some additional information on this technique. The structured light optical measurement technique has been evaluated extensively through the nozzle fabrication cycle for interim process inspections to understand geometric changes between operations, quality control, reverse engineering and match machining or adaptive machining.

The goal of near net shape fabrication of components is to minimize material required for removal during machining. Structured light has been used for predictive machining operations to precisely and accurately determine what surfaces will properly clean up. This scan data provided interim process checks provided visual indications for the operator to determine when the final pass was being made and tool wear for each of the passes. An example of the predictive machining strategy for freeform nozzle liners in shown in Figure 14. The nozzle was scanned in the as-built freeform deposition state and "digital" machining completed with varying depth passes. This allowed an understanding of what surfaces were cleaning up during the machining and can be seen in red (fully machined) in the referenced figure. Additionally, the scan data allows for real-time changes to set up machining datums and alignments and changes in tool paths based on scan data. This process is often referred to as adaptive machining since the machining strategy can be modified real-time based on the geometric surface scan data.

These inspection technologies have demonstrated that they are integral to rapid fabrication of and cost reduction for nozzles. The structured light and photogrammetry techniques are portable and can be used while components are still set up on the machine or during other fabrication operations. Additionally, these techniques have been used for digital assemblies while nozzle subcomponents are manufactured at different locations. This eliminates critical moves and lifts of hardware and dry-fit assemblies and issues can be fixed while components are at the specialty supplier or fabrication sequence cell. These techniques provide integral information on the deformation of the nozzle subassembly during machining and heat treatment operations and are being explored for adaptive machining. 


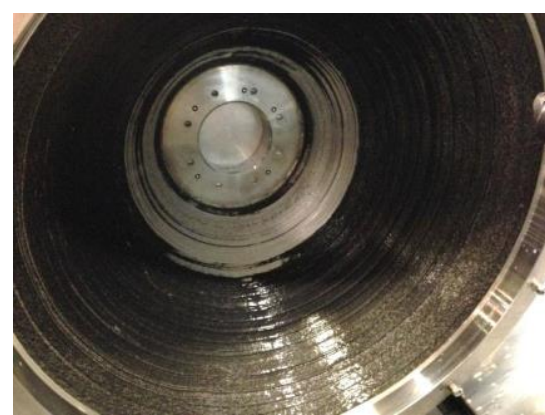

$1^{\text {st }}$ Pass

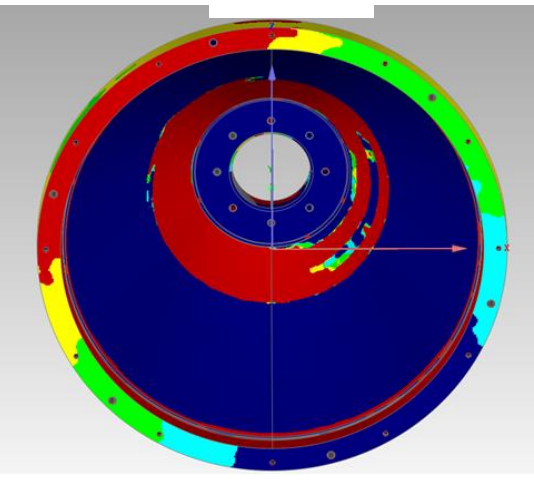

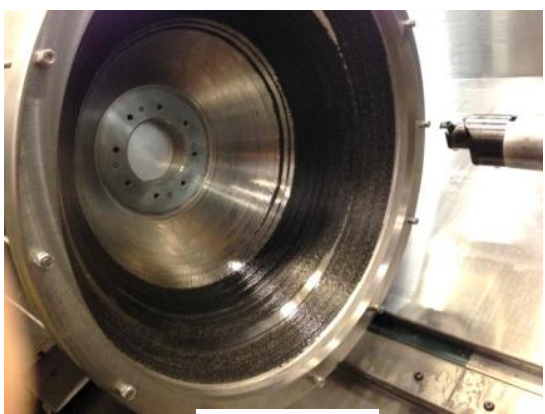

$2^{\text {nd }}$ Pass

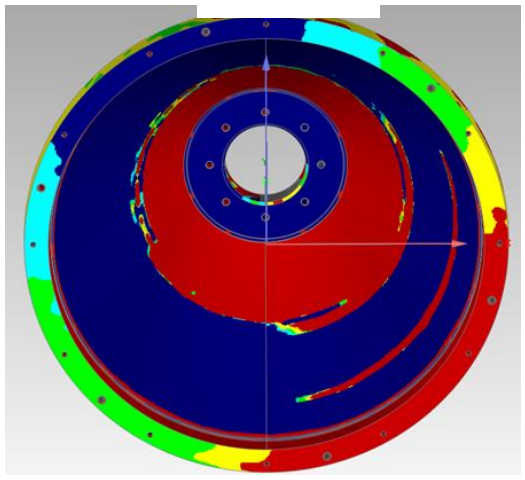

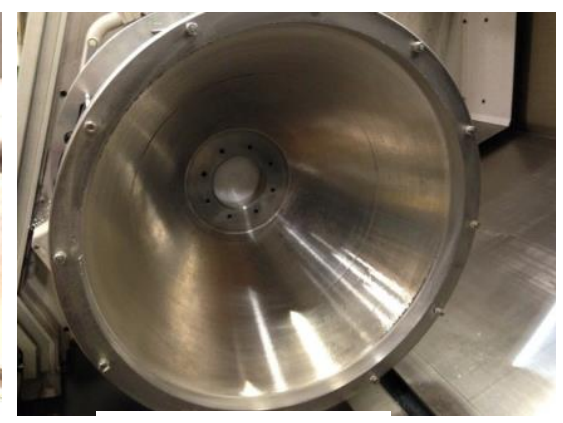

Within 20 mils

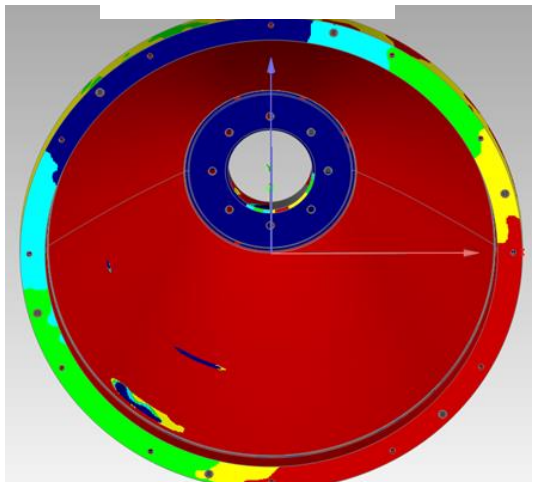

Figure 14. Predictive machining of nozzle liner using interim structured light scan data to determine cleanup of surfaces.

\section{Conclusion}

NASA MSFC has investigated and developed a series of techniques targeting large-scale channel wall nozzles. These techniques can be used for the formation of near net shape liners, machining/forming of the internal coolant passages and closeouts of the coolant passages.

MSFC has completed fabrication of Inconel 625 freeform liners using the blown powder deposition process. This process has demonstrated the ability to rapidly form contoured shapes and subsequent machining and further processes of these liners. Mechanical testing and metallography has been completed on these liners and shown to meet material requirements.

Abrasive Water Jet Milling (WJM) has been demonstrated as a potential replacement method for channel slotting or end milling. A series of components have been fabricated using this technique and have met all design intents. WJM has shown several advantages over traditional techniques, including:

- Reduced hot wall thicknesses to 0.012 " or less

- Significantly increased milling rates/reduced time for difficult-to-machine materials, such as Superalloys

- Ability to meet required tight tolerances in channels and hot wall

- Increased complexity in channel geometries to increase performance

A series of closeout techniques were evaluated, focusing on large-scale nozzle applications. The techniques that were evaluated for closeouts included explosive bonding, freeform additive closeouts and cold spray closeouts. The explosive bonding and freeform additive deposition closeouts demonstrated significant potential to be used for large scale applications. The techniques have demonstrated the ability to closeout coolant channels in a variety of alloys and metallographic and mechanical testing have helped confirm the adequacy of the bonds. The cold spray technology has shown potential for closeout at a specimen level, but requires significant development to advance to a component level. These techniques all show potential for forming nozzles rapidly, enabling cost and schedule reductions for current and future engine applications.

NASA MSFC has current and future development tasks in process that expand on the techniques presented in this paper. The freeform liner deposition technology, as well as material property and characterization, will continue to be evaluated and a series of subscale nozzles is being completed to further demonstrate this process. A series of 
experiments are being conducted on various stainless steel and Superalloys for the explosive bonding process and freeform closeout technique. This research is to further optimize the process and complete metallographic evaluations and mechanical testing of the bonds. Future techniques that will be evaluated as the technology advances are the multipiece SLM nozzles and integral blown-powder deposition nozzles.

\section{Acknowledgments}

The research and development tasks that involve the large-scale channel wall fabrication techniques extend far beyond myself as the lead engineer. I wish to extend a thank you to the many talented engineers that have been involved in these tasks over the last several years. There are several companies and individuals involved in the development of these tasks, enabling us to prove out many of these efforts. Thank you to Albert Hammeke of Laser Technology Associates (LTA) for his continued expertise in laser processing and Bryant Walker of Keystone Synergistic for working to bring additional ideas to the freeform closeout and liner forming process. An acknowledgement to Dave Brasher and the team at High Energy Metals, Inc. (HEMI) for continuing some of the original EXW closeout research. Dan Alberts and the team at Ormond LLC have pushed the boundaries of abrasive jet milling and collaborated on many of our designs and ideas and we thank you for your expertise.

A huge thank you to Will Brandsmeier, as the lead designer on many of these efforts, for allowing me to make several changes to designs on the fly and your questioning of new ideas and valuable inputs. Thank you to Jeff Clounch and the team at 4705 for contributing to many of these efforts. An additional acknowledgement to the individuals involved in structured light scanning that have helped with dimensional checks and match machining: Brian West and John Ivester. I wish to acknowledge the project office that continues to push needs for technology and offers leadership, including Steve Wofford, Carol Jacobs, Mike Shadoan and Andy Hardin. Also, thank you to the many other engineers at MSFC that engage in technical discussions and that have contributed to these various techniques: Gregg Jones, Chris Protz, Sandy Elam Greene, Brad Bullard, Grace Belancik, Warren Peters and Greg Barnett.

\section{References}

${ }^{1}$ Protz, C., Bowman, R., Cooper, K., Fikes, J., Taminger, K., \& Wright, B. (2014). Additive Manufacturing of Low Cost Upper Stage Propulsion Components. JANNAF Additive Manufacturing for Propulsion Applications Technical Interchange Meeting (TIM); 3-5 Sept. 2014; Huntsville, AL.

${ }^{2}$ Greene, S. E. (2015). "Summary of LOX/CH4 Thruster Technology Development at NASA/MSFC". Paper presented at $62^{\text {nd }}$ JANNAF Propulsion Meeting $/ 8^{\text {th }}$ Liquid Propulsion Subcommittee, June 1,2015 . Nashville, TN.

${ }^{3}$ EOS GmbH Electro Optical Systems. (2016). EOS M 400 for Additive Manufacturing for the Industrial Production of High-Quality Large Metal Parts. - EOS. Retrieved May 10, 2016 from http://www.eos.info/systems_solutions/metal/systems_equipment/eos_m_400

${ }^{4} \mathrm{X}$ line 2000R. (2016). Retrieved May 10, 2016, from http://www.concept-laser.de/en/maschinen.html Concept Laser.

${ }^{5}$ Gradl, P. R., Youngblood, A. D., Componation, P. J., \& Gholston, S. E. (2009). Considering risk within net present value: calculations for government projects. The Engineering Economist, 54(2), 152-174.

${ }^{6}$ Sack, W., Kurosu, A., Sunakawa, H., Noda, K., Ogawara, A., Onga, T. and Negoro, N., "LE-X Prototype Main Combustion Chamber Development Progress," The 28th International Symposium on Space Technology and Science, Okinawa, Japan, Jun. 2011.

${ }^{7}$ Hanna, S. G. (2004). Integrated Powerhead Demonstration (IPD). IHPRPT Phase I Cryoboost Demo. Air Force Research Laboratory, Edwards AFB, CA. . Retrieved from http://www.dtic.mil/dtic/tr/fulltext/u2/a430218.pdf.

${ }^{8}$ Fint, J., M. Hankins, M. Jew, D. Ulmer, B. Wherley, D. Romine, F. Kuck, and D. Ades. Rocket Engine Nozzle and Method of Fabricating a Rocket Engine Nozzle Using Pressure Brazing. Pratt \& Whitney Rocketdyne, Inc., assignee. Patent US 7596940 B2. 6 Oct. 2009.

${ }^{9}$ Fint, J., M. Hankins, M. Jew, D. Ulmer, B. Wherley, D. Romine, F. Kuck, and D. Ades. Method of fabricating a rocket engine nozzle using pressure brazing. United Technologies Corporation, assignee. Patent US 8127443 B2. 6 Mar 2012. 
${ }^{10}$ Fint, J., Kuck, F., Sciorelli, F. (2005). Development of Channel Wall Nozzles for Use on Liquid Propellant Rocket Engine. 41st AIAA/ASME/SAE/ASEE Joint Propulsion Conference \& Exhibit, Joint Propulsion Conferences, Tucson, Arizona. AIAA-2005-4371.

${ }^{11}$ Holmes, R., Elam, S., McKechenie, T., and Hickman, R. Paper Session I-A - Robust Low Cost Liquid Rocket Combustion Chamber By Advanced Vacuum Plasma Process (April 30, 2002). The Space Congress ${ }^{\circledR}$ Proceedings. Paper 8. http://commons.erau.edu/space-congress-proceedings/proceedings-2002-39th/april-30-2002/8

${ }^{12}$ Holmes, R., T. McKechnie, C. Power, R. Daniel, and R. Saxelby. Method of Fabricating a Rocket Engine Combustion Chamber. The United States Of America As Represented By The Administrator Of The National Aeronautics And Space Administration, assignee. Patent US 5249357 A. 5 Oct. 1993.

${ }^{13}$ Boman, A., Haggander, J., \& Hass, J. (1999). Laser welded channel wall nozzle design, manufacturing and hot gas testing. 35th AIAA Joint Propulsion Conference and Exhibit. doi:10.2514/6.1999-2750

${ }^{14}$ Lundgren, J. Method for Manufacturing Outlet Nozzles for Rocket Engines. Volvo Aero Corporation, assignee. Patent US 6945032 B2. 20 Sept. 2005.

${ }^{15}$ Gradl, P.R., Kopicz, C.F., Hulka, J.R. "Design and Fabrication Development of J-2X Engine Metallic Nozzle Extension" Paper presented at $62^{\text {nd }}$ JANNAF Propulsion Meeting $/ 8^{\text {th }}$ Liquid Propulsion Subcommittee, June 1 , 2015. Nashville, TN

${ }^{16}$ Farinia Group. "Industrial Production Systems for Metal Additive Manufacturing." Industrial Production Systems for Metal Additive Manufacturing. 2015. Web. 18 May 2016.

17 Uziel, A. (2016). Looking at Large-Scale, Arc-Based Additive Manufacturing. American Welding Society Welding Journal, April 2016, Vol. 94, No. 4, 42-46.

${ }^{18}$ Lundgren, J., and M. Hallqvist. Method of Manufacturing a Wall Structure and a Machining Tool. Volvo Aero Corporation, assignee. Patent US 8448335 B2. 28 May 2013.

${ }^{19}$ Ding, D., Pan, Z., Cuiuri, D., \& Li, H. (2015). Wire-feed additive manufacturing of metal components: technologies, developments and future interests. The International Journal of Advanced Manufacturing Technology, $81(1-4), 465-481$.

${ }^{20}$ Frazier, W. E. (2014). Metal additive manufacturing: a review. Journal of Materials Engineering and Performance, 23(6), 1917-1928.

${ }^{21}$ Damgaard, T., Brox, L., \& Hallberg, M. (2006). Demonstration of a Laser Welded Channel Wall Nozzle Vulcain 2 Scale. 42nd AIAA/ASME/SAE/ASEE Joint Propulsion Conference \& Exhibit. doi:10.2514/6.2006-4369

${ }^{22}$ Pattee, H., Linse, V. (1976). Development of Explosive Welding Procedures to Fabricate Channeled Nozzle Structures. Report No. NASA-CR-144977 under National Aeronautics and Space Administration contract NAS113320 by Battell Labs, Columbus.

${ }^{23}$ Linse, V.D. (1974). The Application of Explosive Welding to Turbine Components. Gas Turbine Conference \& Products Show, Zurich, Switzerland, March 30 - April 4, 1974. ASME 74-GT-85.

${ }^{24}$ Smith, E., et al. (1971). Development of Explosive Welding Techniques for Fabrication of Regeneratively Cooled Thrust Chambers for Large Rocket-Engine Requirements. Report No. NASA-CR-72878 under National Aeronautics and Space Administration Contract NAS3-10306.

${ }^{25}$ Matthews, S. J., \& Savage, W. F. (1971). Heat Affected Zone Infiltration by Dissimilar Liquid Weld Metal. Weld Journal, 50(4), 174.

${ }^{26}$ Haynes, J., \& Karthikeyan, J. (2003). Cold spray copper application for upper stage rocket engine design. Thermal Spray 2003: Advancing the Science and Applying the Technology, 5-8.

${ }^{27}$ Karthikeyan, J. (2004). Cold spray technology: International status and USA efforts. Report from ASB Industries Inc., Barbeton, OH, 44203, 1-14.

${ }^{28}$ Butler, T. (2012). Liquid Accelerated Cold Spray. CSAT Meeting Presentation. Phase II SBIR Contract W911QX-11-C-0002. October 20, 2012. Obtained from: http://www.coldsprayteam.com/files/Tom\%20Butler_\%20Ormond.pdf

${ }^{29}$ Ivanov, A. D., Nikolaev, A. K., Kalinin, G. M., \& Rodin, M. E. (2002). Effect of heat treatments on the properties of CuCrZr alloys. Journal of Nuclear Materials, 307, 673-676.

${ }^{30}$ Gradl, P.R. "Application of Optical Measurement Techniques during Fabrication and Testing of Liquid Rocket Nozzles.” Paper presented at $62^{\text {nd }}$ JANNAF Propulsion Meeting/8 $8^{\text {th }}$ Liquid Propulsion Subcommittee, June 1, 2015. Nashville, TN. 